\title{
Long term angiographic follow up, cardiac events, and survival in patients undergoing percutaneous transluminal coronary angioplasty
}

\author{
SJEF M P G ERNST, TACO A VAN DER FELTZ, EGBERT T BAL, \\ LEO VAN BOGERIJEN, EDUARD VAN DEN BERG, CARL A P L ASCOOP, \\ H W THIJS PLOKKER \\ From the Department of Cardiology, St Antonius Hospital, Utrecht/Nieuwegein, the Netherlands
}

SUMMARY The results of percutaneous transluminal coronary angioplasty were studied in $1352^{\circ} \stackrel{\circ}{\triangle}$ consecutive patients. The angioplasty procedure was angiographically successful in $1163(86 \%) \vec{z}$ patients and the success rate increased gradually with time. There were no significant differences in success rates in different vessels or indications. The success rate for repeat coronary angio- $\mathcal{O}$ plasty was $92 \%$. In $85 \%$ of the patients the clinical course was uncomplicated. Myocardial $\vec{\emptyset}$ infarction occurred in $3.6 \%$, emergency coronary bypass grafting in $2.6 \%$, elective bypass. ${ }^{\infty}$ surgery in $4.6 \%$, and there were 10 deaths $(0.7 \%)$. There were 16 deaths (10 non-cardiac) during응 follow up in the 1163 patients in whom the first procedure was successful. Actuarial analysis showed that after a first angioplasty 77.9\% remained free of symptoms and cardiac events for five years and that after a second angioplasty $76 \%$ did so. Angiographic follow up showed restenosis $\frac{0}{\varnothing}$ in $24 \%$ of patients but the overall clinical success rate was $86.2 \%$. On the basis of the intention $\cong$ to treat the procedure was successful in $74.3 \%$ of all 1352 patients. Coronary artery bypass $\overrightarrow{\overrightarrow{0}}$ surgery was eventually performed in $11.6 \%$ of all patients.

The long term angiographic success rate of coronary angioplasty is higher than previously? suggested.

We report the angiographic and long term clinical results in a large number of consecutive patients who were treated with percutaneous coronary angioplasty.

\section{Patients and methods}

\section{PATIENTS}

From April 1980 to October 1985, 1889 patients had coronary angioplasty at the St Antonius Hospital in Utrecht (which is now in Nieuwegein). We have included only those patients in whom follow up lasted at least six months-that is 1352 patients who had coronary angioplasty before 1 January 1985. Eighty per cent of the patients were men.

All the patients had angina pectoris that responded poorly to medical treatment. In all

Requests for reprints to Dr HW Thijs Plokker, St Antonius Hospital, PO Box 2500, 3430 EM Nieuwegein, the Netherlands.

Accepted for publication 21 April 1986 patients with stable angina signs of myocardialo ischaemia were demonstrated by excercise electrocardiographic studies or exercise scintigraphy. Sev-ô enty two per cent of the patients had angina pectoris $₹$ of Canadian Heart Class III or IV. In $4 \%$ of the을 patients the severity of angina could not be coded $\triangle$ properly because of recent thrombolytic (strep-을. tokinase) treatment.

Coronary angioplasty was performed as an elec- - tive procedure in $896(66 \%)$ patients and in 355 O $(26 \%)$ patients it was performed because of $\omega$ impending myocardial infarction, which was defined as pain at rest accompanied by electrocardiographico ST-T changes without signs of myocardial necrosis $\mathbb{D}$ occurring less than one week before the angioplasty? procedure. Seventy two $(5 \%)$ patients had had streptokinase treatment because of an acute myo- $\frac{\text { के }}{\mathrm{D}}$ cardial infarction more than twelve hours before? coronary angioplasty and in 17 patients the angio- $\triangle$ plasty attempt took place immediately after thrombolytic treatment. In 12 patients with an acuteo 
myocardial infarction the acutely occluded vessel was approached with the balloon catheter without previous thrombolytic treatment.

Six per cent (82 cases) of the patients had aortocoronary bypass grafts and 9\% (113 cases) had previous percutaneous transluminal coronary angioplasty. Nineteen per cent (259 cases) had suffered a myocardial infarction in the area related to the stenosis that was treated by angioplasty, $11 \%$ (143 cases) had an infarction elsewhere, and 1\% (16 cases) had suffered myocardial infarctions both in stenosis related and unrelated areas.

\section{ANGIOGRAPHIC PROFILE}

Seventy per cent of the patients had single vessel disease. Left ventricular function was normal in $55 \%$ of the patients. Complete revascularisation (successful dilatation of all stenoses $>50 \%$ ) was thought to be possible in $78 \%$ of the patients. The severity of the stenosis was assessed by the means of multiple (angulated) angiographic views. The luminal diameter of the vessel at the narrowest portion of the stenosis was expressed as the percentage of the luminal diameter of the adjacent (normal) diameter, measured from a 12 fold magnified projection of the cine film on which the vessel contours were outlined by hand and measured with mechanical callipers.

\section{PROCEDURE}

Transluminal coronary angioplasty was performed via the femoral artery in $97 \%$ of the patients. After the first 361 patients had been treated a steerable balloon catheter system was used exclusively. In patients with multiple vessel disease the site considered to be the primary cause of the symptoms was first attempted. Multiple vessel disease was defined as stenoses of $>50 \%$ in more than one major epicardial vessel.

An attempt at angioplasty was considered to be a success if the stenosis was reduced by $>20 \%$ of the luminal diameter without complications that lead to myocardial infarction, coronary bypass operation, or death.

\section{MEDICATION}

After the first 100 patients all patients were routinely treated with anticoagulants, which ideally were started before angioplasty, and with heparin, dextran, and aspirin during the procedure, and anticoagulants plus either aspirin or dipyridamole for at least six months after the procedure.

\section{FOLLOW UP ANGIOGRAPHY}

Follow up angiography was performed in $62 \%$ (723) of cases. All patients were encouraged to have a fol- low up angiographic examination six months after the angioplasty. Naturally the proportion of patients with symptoms in the angiographic follow up group was higher than it was in the initial group. A restenosis was defined as a loss of $>50 \%$ of the initial gain.

\section{STATISTICAL ANALYSIS}

The significance of differences was assessed by $\chi^{2}$ analysis. Event free actuarial curves were based on the absence of recurrence of angina pectoris, myocardial infarction, repeat angioplasty, coronary bypass grafting, and death. The significance of difference between actuarial curves were assessed by the log-rank or Mantel-Haenszel test.

\section{Results}

The angioplasty attempt was successful in 1163 $(86 \%)$ patients. The success rate was $87 \%$ $(1281 / 1480)$ for stenoses. There was a clear increase in success rate with time and after the introduction of the steerable angioplasty system. There were no significant differences in success rates in different vessels.

The success rates in patients with stable angina and with impending myocardial infarction were not significantly different. The success rate for a repeat angioplasty was $92 \%$. The success rate in patients with an immediate coronary angioplasty at the time of an acute myocardial infarction was $92 \%(11 / 12)$, the success rate for patients with an acute myocardial infarction who had coronary angioplasty immediately after thrombolytic treatment was $100 \%$ (17/17), and the success rate in patients who had coronary angioplasty $\geqslant 12$ hours after thrombolysis was $87.5 \%(63 / 72)$.

Table 1 shows the clinical course in all 1352 patients. In $85 \%$ it was uncomplicated. Myocardial infarction occurred in $3.6 \%$, emergency coronary

Table 1 Clinical course in 1352 patients

\begin{tabular}{lcc}
\hline Course & No & $\%$ \\
\hline Uneventful & 1146 & 85 \\
MI: & 20 & $1 \cdot 5$ \\
STT & 29 & $2 \cdot 1$ \\
QRS & 36 & $2 \cdot 6$ \\
Emergency CABG & 64 & 4.6 \\
Elective CABG & 10 & 0.7 \\
Deaths & 48 & 3.5 \\
Minor problems & & \\
\hline
\end{tabular}

STT, myocardial infarction without QRS changes; QRS, myocardial infarction with new $Q$ waves on the electrocardiogram; $\mathrm{CABG}$, coronary artery bypass grafting.

Minor problems include successful redilatations after occlusion of the vessel without myocardial infarction, ST changes without an increase in serum enzyme activity, and arrhythmias.

$\star$ One patient died. 
artery bypass grafting was done in $2 \cdot 6 \%$ (one of these 36 patients died after operation), elective bypass surgery was performed in $4.6 \%$, and there were 10 deaths $(0.7 \%)$. Angioplasty of the proximal left anterior descending artery was attempted in all but two of the patients who died, and it appeared to be successful initially. Minor problems such as ST changes without signs of myocardial infarction or arrhythmias occurred in $3.5 \%$ of the patients.

CLINICAL FOLLOW UP

Sixteen of the 1163 patients in whom the initial angioplasty procedure was successful died during follow up. There were six proven or suspected cardiac deaths and 10 proven non-cardiac deaths. Coronary bypass surgery had to be performed because of recurrence or progression of coronary artery disease or both in $58(5 \%)$ patients. A second angioplasty was attempted in $95(8 \%)$ patients.

In $13 \%$ of patients coronary angioplasty was performed in another vessel segment because of progression of atherosclerotic disease. Acute myocardial infarction occurred in the area related to the angioplasty site in six $(0.5 \%)$ patients and in a nonrelated area in five $(0.4 \%)$ patients. One patient who had successful angioplasty after thrombolytic treat- ment eventually underwent heart transplantatio because of persisting severe left ventricular failure:Table 2 shows the late events.

Figure 1 shows the actuarial event free curve fof all 1163 patients in whom the first coronary angio plasty procedure was successful. Angina generalle. recurred in the first six months, after this there wero only a few cases of recurrence, and after five years $77.9 \%$ of the patients were free of symptoms an 8 events. The mean follow up was 23.8 months; Exclusion of patients with previous coronary artery surgery, in whom symptoms recurred more oftents

Table 2 Late events in 1163 patients in whom a first coronary angioplasty procedure was successful

\begin{tabular}{|c|c|c|}
\hline Event & No & $\%$ \\
\hline $\begin{array}{l}\text { Total late mortality: } \\
\text { Cardiac } \\
\text { Non-cardiac } \\
\text { ACBG } \\
\text { Re-PTCA } \\
\text { PTCA other segments } \\
\text { AMI } \\
\text { AMI (non-related area) } \\
\text { Heart transplantation }\end{array}$ & $\begin{array}{r}16 \\
6 \\
10 \\
58 \\
93 \\
13 \\
6 \\
5 \\
1\end{array}$ & $\begin{array}{l}1 \cdot 4 \\
0 \cdot 5 \\
0 \cdot 9 \\
5 \\
8 \\
1 \\
0 \cdot 5 \\
0 \cdot 4\end{array}$ \\
\hline
\end{tabular}

ACBG, aortocoronary bypass grafting; PTCA, percutaneous transluminal coronary angioplasty; AMI, acute myocardią infarction.

\section{No of patients entering interval}

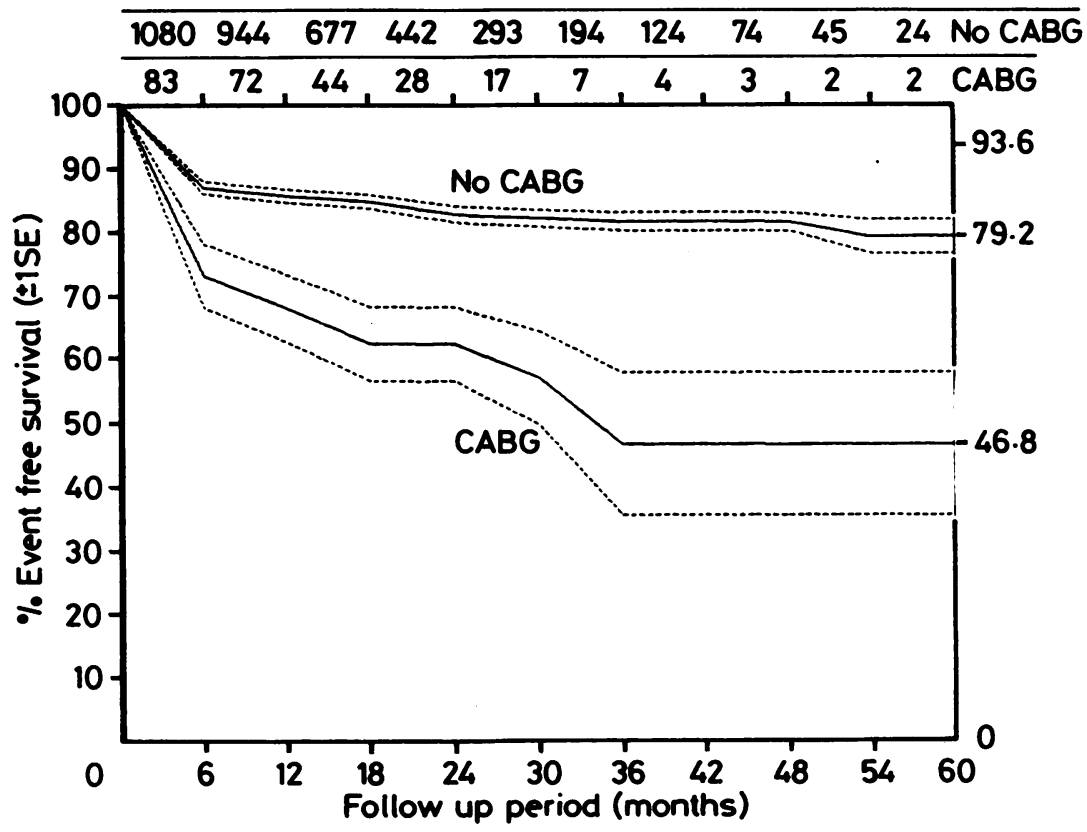

Fig 1 Event free survival (actuarial) after successful coronary angioplasty in 1163 patients. No CABG, patients who had not previously undergone coronary bypass surgery. $C A B G$, patients who had previously undergone coronary bypass surgery. Event free, no angina, myocardial infarction, death, redilatation, or bypass surgery. Broken lines indicate $\pm 1 S E$. 
produced a more level event free curve with $79.2 \%$ of the remaining patients being symptom free and having had no myocardial infarction, repeat coronary angioplasty, or coronary bypass grafting. Only $46.4 \%$ of the patients who had coronary bypass grafts were free of symptoms five years after angioplasty (p $<0.001$ (fig 1)).

Patients who had coronary angioplasty because of stable angina pectoris and those with impending myocardial infarction had similar event free curves. After five years $78.6 \%$ of the patients with impending myocardial infarction at the time of successful coronary angioplasty are symptom free as are $74.5 \%$ of the patients with stable angina at the time of successful coronary angioplasty. Any symptoms associated with angiographic evidence of restenosis generally recur within six months (mean (SD) 4.8 $(6 \cdot 8))$ of angioplasty. In the 40 patients without angiographic evidence of restenosis but with progression of the disease elsewhere symptoms recurred $17.6(14.5)$ months after angioplasty.

The recurrence of angina was not influenced by the presence of complete or incomplete revascularisation after coronary angioplasty. This may be because the study group contained many patients with an occlusion elsewhere that had been present for a long time and was no longer causing symptoms.

After exclusion of patients who had had previous coronary artery bypass surgery, $76 \%$ of the patients who had a second coronary angioplasty because of a recurrence of the stenosis after a successful first procedure were angina free five years after the second procedure (mean follow up of only 17.4 months). This result is not statistically different from that $(79.2 \%)$ in the patients who were symptoms free five years after a first coronary angioplasty.

\section{ANGIOGRAPHIC FOLLOW UP}

Angiographic follow up examination was performed in $728(63 \%)$ of the 1163 patients in whom angioplasty had been initially successful a mean of 4.5 months before. In $98 \%$ of the symptom free patients who had angiographic follow up there was no restenosis. Twenty five per cent of the patients who had angiographic follow up had symptoms and $75 \%$ of these patients had angiographic evidence of recurrence. Of the patients who had no angiographic follow up, $96 \%$ were symptom free. Restenosis was seen 185 times in $174(24 \%)$ patients. Even if a restenosis is defined as a stenosis of $>50 \%$ of the luminal diameter, the restenosis rate remains approximately the same (177 times in 167 patients). Figure 2 shows the difference between the degree of stenosis immediately after and late after a successful dilatation. Of the 797 stenoses that were successfully

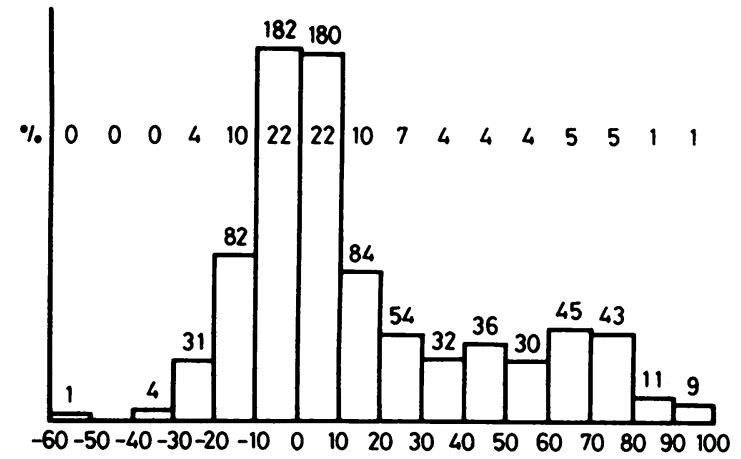

Fig 2 The difference between the degree of stenosis immediately after and late after successful coronary angioplasty. When the stenosis decreased further with time the difference has a minus sign. Recurrences, therefore, are on the right hand side of this diagram.

dilated in these 728 patients, the main difference between the initial and follow up angiographic appearance was a mean (1SD) decrease in lumen diameter of $14 \cdot 1(29 \cdot 0 \%)$. At repeat angiography 528 segments $(66.2 \%)$ were unchanged (a change in diameter of $\geqslant 20 \%$ compared with the luminal diameter immediately after dilatation). These data suggest that the degree of stenosis at the end of the procedure does not predict the result at follow up angiography. Only two $(8 \%)$ of the 25 patients who had two follow up angiograms had a late recurrence. Angiography at follow up showed progression of disease elsewhere in $10 \%$ of patients in whom angioplasty had been successful. There were no differences in the restenosis rate between patients with stable or unstable angina at the time of angioplasty. Repeat balloon dilatation was successful in $92 \%$ of 115 restenoses. Fifty one of these patients had angiographic follow up. A second restenosis occurred in $17(33 \%)$ patients.

In 17 patients who had a successful coronary angioplasty immediately after thrombolytic treatment, 10 had a follow up angiogram and recurrences were seen in three. In 63 patients who had a successful coronary angioplasty some time after thrombolytic treatment, 46 had a follow up angiogram and recurrences were seen in seven $(15.2 \%)$. Eight of the 11 patients with successful coronary angioplasty at the time of an acute myocardial infarction without thrombolytic treatment had a follow up angiogram and recurrences were seen in four $(50 \%)$.

\section{Discussion}

Many reports indicate that balloon coronary angioplasty is effective in dilating coronary artery stenoses and relieving the associated symptoms of angina. This report suggests not only that short term but 
also that longer term relief of angina pectoris can be achieved. Patients who remain symptom free for the first six months after successful coronary angioplasty are likely to remain free of angina for the next five years. Only $2 \%$ of the symptom free patients who had repeat angiography showed evidence of restenosis without infarction or symptoms.

In the patients who have important restenosis at the site of the coronary angioplasty, anginal complaints usually recur within six months, whereas in the patients without angiographic evidence of recurrence but with considerable progression of the disease elsewhere symptoms usually occur later than one year after coronary angioplasty. This suggests that if symptoms recur after six months they are more likely due to progressive disease elsewhere rather than restenosis. This accords with the angina free curve after successful coronary angioplasty (without previous coronary artery bypass grafting) which demonstrates a rather steep drop to $87 \%$ in the first six months, after which the percentage of angina free patients drops to $81 \%$ over the next four and a half years. We do not know why $86 \%$ of our patients without previous coronary bypass surgery were symptom free after one year whereas in another report (from the Mayo Clinics) only $74 \%$ of similar patients remained free of angina after one year. ${ }^{1}$ The medical treatment after coronary angioplasty is not specified in the Mayo Clinic report and it may be that differences in medical treatment have influenced the outcome in these two studies. Also the choice of the balloon size, pressure gradient determination at the end of the procedure, and other technical differences may influence the results. Reported percentages of angiographically proven recurrences of stenosis vary widely (range $12-47 \%)^{2-4}$ and depend on the definition of restenosis. Systematic angiographic follow up data are generally lacking except in the studies of Kaltenbach $e t a l^{23}$ and Jutzy $e t a l^{5}$ and the percentage of patients with a follow up angiography in most other series varies widely. Patient selection must have influenced the percentage $(24 \%)$ of angiographic recurrences in our series because patients with symptoms had repeat angiography more often than patients without $(\mathrm{p}<0.001)$.

On the basis of intention to treat $1005(14.3 \%)$ out of the original 1352 patients had a completely successful angioplasty. Neither the initial success rate nor the recurrence rates for angina pectoris, myocardial infarction, or angiographic restenoses were different in patients with stable or unstable angina at the time of coronary angioplasty. This accords with reports that coronary angioplasty is effective in patients with unstable angina that is refractory to medical treatment. ${ }^{67}$ Our study was not designed to investigate the role of coronary angioplasty afte $\frac{\stackrel{0}{2}}{2}$ thrombolytic treatment for acute myocardia: infarction. In our series there was a high initia秀 success rate for coronary angioplasty during acute myocardial infarction and immediately after throm $\frac{\overline{0}}{0}$ bolytic treatment. It appears, however, that long term patency rates are higher if coronary angioplast can be postponed for 12 hours or more after success ful thrombolytic treatment.

If a restenosis occurs, a second coronary angio. $\vec{\circ}$ plasty can be performed effectively and safely in most cases. In the 115 restenoses for which a seconf coronary angioplasty was done, both the initial suc cess rate $(92 \%)$ and the late angiographic patency rate resemble those of the first coronary angioplasty $y_{\omega}$ Forty eight months after the second dilatation $76 \%$ of these patients were angina free. This accords witho the good results obtained with repeat coronarg angioplasty in other series. ${ }^{8}$

Coronary artery bypass surgery was eventualls performed in $158(11.6 \%)$ patients-in 64 because of failure of the coronary angioplasty, in $36(2.6 \%)$ because of an emergency during the angioplastyo attempt, and in 58 because of recurrence of thê stenosis and/or progression of the disease elsewhere after successful coronary angioplasty. These result indicate that angioplasty could prevent or postpone coronary bypass surgery in many patients with angina pectoris.

\section{Conclusion}

Angiographically successful coronary angioplast offers a better chance of long lasting relief of symp toms than previously suggested. We do not know whether our figures were influenced more by the technical aspects than by medical treatment aftes angioplasty. If a restenosis occurs a second coronary angioplasty can be done with good initial and late results.

\section{References}

1 Mabin TA, Holmes DR, Smith HC, et al. Follow-u clinical results in patients undergoing percutaneous transluminal coronary angioplasty. Circulation 1985;71:754-60.

2 Kaltenbach M, Kober G, Schmidt-Moritz A, Scheref D. Rezidivhaufigkeit nach erfolgreicher trans? luminaler Koronarangioplastie. Dtsch Met Wochenschr 1983;108:1387-90.

3 Kaltenbach M, Kober G, Scherer D, Vallbracht $C^{\infty}$ Recurrence rate after successful coronary angio=0 plasty. Eur Heart $\mathcal{F}$ 1985;6:276-81.

4 Dangoisse V, Val PG, David PR, et al. Recurrence of stenosis after successful percutaneous translumina coronary angioplasty (PTCA) [Abstract]. Circulation 1982;66(suppl II):331. 
5 Jutzy KR, Berte LE, Alderman EL, Ratts J, Simpson JB. Coronary restenosis rates in a consecutive patient series one year post successful angioplasty [Abstract]. Circulation 1982;66(suppl II):331.

6 De Feyter PJ, Serruys PW, Van den Brand M, et al. Emergency coronary angioplasty in refractory unstable angina. $N$ Engl $f$ Med 1985;313:342-6.
7 Meyer J, Schmitz HJ, Kiesslich T, et al. Percutaneous transluminal coronary angioplasty in patients with stable and unstable angina pectoris: analysis of early and late results. Am Heart $\mathcal{F}$ 1983;106:973-80.

8 Meier B, King SB III, Gruentzig AR, et al. Repeat coronary angioplasty. $\mathrm{f} \mathrm{Am}$ Coll Cardiol 1984;4: 463-6. 